\title{
In spermatozoa, Stat1 is activated during capacitation and the acrosomal reaction
}

\author{
Yadira Bastián, Armando Zepeda-Bastida, Salvador Uribe ${ }^{1}$ and Adela Mújica \\ Departamento de Biología Celular, Centro de Investigación y de Estudios Avanzados del Instituto Politécnico Nacional \\ (Cinvestav-IPN), México DF, Mexico and ${ }^{1}$ Instituto de Fisiología Celular, Universidad Nacional Autónoma de México, \\ México DF, Mexico
}

Correspondence should be addressed to A Mújica; Email: adelam@cell.cinvestav.mx

\begin{abstract}
A role for sperm-specific proteins during the early embryonic development has been suggested by a number of recent studies. However, little is known about the participation of transcription factors in that stage. Here, we show that the signal transducer and activator of transcription 1 (Stat1), but not Stat4, was phosphorylated in response to capacitation and the acrosomal reaction (AR). Moreover, Stat1 phosphorylation correlated with changes in its localization: during capacitation, Stat1 moved from the cytoplasm to the theca/flagellum fraction. During AR, Stat1 phosphorylation increased again. In addition, blocking protein kinase A (PKA) and PKC during capacitation abolished both phosphorylation and migration of Stat1. Our results show tight spatio-temporal rearrangements of Stat1, suggesting that after fertilization Stat1 participates in the first rounds of transcription within the male pronucleus.
\end{abstract}

Reproduction (2007) 134 425-433

\section{Introduction}

The signal transducer and activator of transcription (Stat) protein family mediates transcription of several cytokineinducible genes and growth factors (Darnell et al. 1994, Leaman et al. 1996, Darnell 1998, Schindler 1999, Ihle 2001). In receptor-bound Stats, a conserved tyrosine residue located in the $\mathrm{C}$-terminal domain is phosphorylated by the Janus kinase (Jaks). Then, the $\mathrm{SH} 2$ domain in each of two Stats assembles through reciprocal phosphotyrosine/ $\mathrm{SH} 2$ interactions leading to dimerization. Once dimerized, the proteins are translocated into the nucleus, where they regulate transcription of several different genes. So far, seven Stat proteins have been identified: Stat $1-6$ and Stat5b (Darnell 1997, O'Shea et al. 2002).

Research in interferon-mediated signaling pathways led to the discovery of Stat1 and Stat2. Interferon (IFN)- $\gamma$ induces Stat1 homodimerization, leading to transcription of $\gamma$ activated sequence (GAS)-driven genes. Both IFN- $\alpha$ and Interferon (IFN)- $\beta$ induce formation of either Stat1 homodimers or Stat1/Stat2 heterodimers (Kisseleva et al. 2002). In addition, Stat1 can be activated either by growth factor-mediated signal pathways, or by a G-protein-coupled receptor (Brivanlou \& Darnell 2002).

In lymphocytes, Stat 4 may be activated by IFN- $\alpha$ or interleukin (IL)-12 (Cho et al. 1996). In T cells, only IL-12 treatment activates Stat4 (Jacobson et al. 1996). In the immune system, Stat4 is also activated by IL-23 (O'Shea et al. 2002).
Even though the spermatozoon is considered as a transcriptionally silent cell, it does contain some transcription factors (Herrada \& Wolgemuth 1997, D'Cruz et al. 2001, Pittoggi et al. 2001). In spermatozoa, the Jak-Stat members detected to date are tyrosine kinase 2 (Tyk2), Stat4 and Stat1 (Herrada \& Wolgemuth 1997, D'Cruz etal. 2001). Stat 4 was identified in the perinuclear theca (PT) of mouse sperm (Herrada \& Wolgemuth 1997).

Freshly ejaculated spermatozoa are unable to fertilize the egg. These cells need to undergo two physiological processes in the female reproductive tract in order to acquire the capacity to fertilize. The first process is known as capacitation. During capacitation, membrane fluidity increases, cholesterol is lost, and intracellular calcium and cAMP concentrations increase; protein phosphorylation occurs and the swimming sperm pattern is modified (Breitbart \& Naor 1999). The second process occurs after gamete capacitation and is known as the acrosome reaction (AR). In AR, the outer acrosomal membrane fuses with the plasma membrane (Yanagimachi 1995). After capacitation and AR, spermatozoa become able to fertilize the egg.

It has become clear that in addition to DNA, sperm cells contribute to the egg with RNA and proteins. These molecules are very likely crucial in the early stages of embryonic development. Following this order of ideas, we decided to test guinea pig spermatozoa for the 
presence of transcription factors and their possible activation during the processes of sperm capacitation and AR. In guinea pig spermatozoa, we determined the presence and location of Stat 1 and Stat 4 , as well as their possible activation during capacitation and AR. Here, we show that Stat1 was phosphorylated both during capacitation and AR. Additionally, during capacitation, the distribution of Stat1 was modified: it increased in the theca/flagellum fraction, while it decreased in the cytoplasm. In addition, in acrosome-reacted sperm, Stat1 was reorganized in the nucleus. In contrast to Stat1, Stat4 was not phosphorylated, neither at capacitation nor at AR. Furthermore, we did not detect any change in its localization pattern.

\section{Materials and Methods}

\section{Antibodies and reagents}

Pyruvic acid, lactic acid, DL-dithiothreitol (DTT), sucrose, Triton X-100, aprotinin, phenylmethylsulfonyl fluoride (PMSF), Tris, sodium orthovanadate, SDS, cetyltrimethylammonium bromide (CTAB), bisindolylmaleimide I $(\mathrm{Bis})$, genistein and EGTA, $N$-[2-(p-bromocynamilamino)etil-]-5-isoquinesulfonamide $(\mathrm{H}-89)$, and genistin were purchased from Sigma. Protein A-agarose and the protease inhibitor cocktail Complete were purchased from Roche. Nitrocellulose membranes, acrylamide, and $N, N^{\prime}$-methylene-bis-acrylamide were purchased from Bio-Rad. The antibodies used were: rabbit polyclonal anti-Stat1 (sc-592), rabbit polyclonal anti-Stat4 (sc-486), and rabbit polyclonal anti- $p$-Tyr (sc-508), all of them from Santa Cruz Biotechnology (Santa Cruz, CA, USA). Horseradish peroxidase (HRP)-labeled anti-rabbit and anti-mouse, tetramethyl-rhodamine isothiocyanate (TRITC)-labeled anti-rabbit were from Jackson Immunoresearch Laboratories Inc. (West Grove, PA, USA). The ECL was obtained from Amersham.

\section{Capacitation and acrosome reaction induction in spermatozoa}

Ductus deferens and cauda epididymal guinea pig spermatozoa were obtained and washed in $154 \mathrm{mM}$ $\mathrm{NaCl}$, as previously described (Trejo \& Mujica 1990). To start capacitation, $35 \times 10^{6}$ sperm cells $/ \mathrm{ml}$ were incubated at $37^{\circ} \mathrm{C}$ in minimal culture medium containing lactate and pyruvate (MCM-PL) without glucose (Rogers \& Yanagimachi 1975). Incubation time varied for each experimental condition (see Results). The acrosome reaction was induced at 90 min of incubation in capacitating medium by adding the calcium ionophore A23187 (1.3 $\mu \mathrm{M})$ and further incubating for $3 \mathrm{~min}$. The sample was centrifuged at $5000 \mathrm{~g}$. Pelleted cells were processed for Western blotting.

\section{Kinase inhibitor treatment}

Spermatozoa at $35 \times 10^{6}$ cells $/ \mathrm{ml}$ were preincubated in $154 \mathrm{mM} \mathrm{NaCl}$ with PKA inhibitor EGTA (1 mM), or H89 $(30 \mu \mathrm{M})$, the PKC inhibitor Bis I $(1 \mu \mathrm{M})$, or the tyrosine kinase inhibitor genistein $(100 \mu \mathrm{M})$ or its inactive homolog genistin $(100 \mu \mathrm{M})$ for $30 \mathrm{~min}$. Then, they were incubated in MCM-PL capacitating medium in the presence or absence of the corresponding inhibitor at the same concentrations.

\section{Sperm nuclei isolation}

For nuclei isolation, a previously described technique was followed (Ocampo et al. 2005) with slight modifications. $\mathrm{NaCl}$-washed spermatozoa were resuspended in buffer A $(50 \mathrm{mM}$ Tris- $\mathrm{HCl}(\mathrm{pH} 7.4)$ plus a commercial mixture of protease inhibitors, Complete, according to the manufacturer's instructions), and treated with $25 \mathrm{mM}$ DTT for $20 \mathrm{~min}$ with constant agitation at $4{ }^{\circ} \mathrm{C}$. Afterwards, $1.2 \%$ of $\mathrm{CTAB}$ was added and the sample was centrifuged for $3 \mathrm{~min}$ at $5000 \mathrm{~g}$ at $4{ }^{\circ} \mathrm{C}$. The pellet (nuclei) was washed thrice by suspension/centrifugation with $1 \mathrm{M}$ sucrose, treated with $5 \mathrm{U}$ heparin for $35 \times 10^{6}$ cells for $15 \mathrm{~s}$, fixed with $1.5 \%$ formaldehyde in PBS, and handled for immunofluorescence.

\section{Immunofluorescence}

Cells or nuclei preparations were fixed with 1.5\% formaldehyde on PBS (Moreno-Fierros et al. 1992). Smears on glass slides were prepared. Then, cells were permeabilized with acetone at $-20^{\circ} \mathrm{C}$ for $7 \mathrm{~min}$ and washed thrice in PBS. Cells were incubated overnight at $4{ }^{\circ} \mathrm{C}$ either with anti-Stat 1 or with anti-Stat 4 antibodies in $1 \%$ BSA in PBS. The binding of the primary antibodies was revealed using appropriate rhodamine-labeled secondary antibodies. The cells were observed in a Zeiss photomicroscope equipped with phase contrast and epifluorescence optics or using a Leica TCS SP2 confocal microscope with Krypton/Argon laser.

\section{SDS-PAGE and Western blotting}

Washed spermatozoa $\left(35 \times 10^{6}\right.$ cell $)$ were solubilized in $1 \mathrm{ml}$ lysis buffer (LB: $50 \mathrm{mM}$ Tris- $\mathrm{HCl}(\mathrm{pH} 7.4), 1 \mathrm{mM}$ EGTA, $1 \mathrm{mM}$ PMSF, Complete, $1 \mu \mathrm{g} / \mathrm{ml}$ aprotinin, $10 \mathrm{mM}$ sodium orthovanadate, $25 \mathrm{mM}$ sodium fluoride, and $1 \%$ Triton $X-100$ ), and then centrifuged for $3 \mathrm{~min}$ at $5000 \mathrm{~g}$ at $4{ }^{\circ} \mathrm{C}$. The supernatants (Triton X-100 extracts) were collected. The pellets were washed thrice with LB without Triton X-100 to remove any contaminant and treated with $25 \mathrm{mM}$ DTT for $20 \mathrm{~min}$ at $4{ }^{\circ} \mathrm{C}$; then $1.2 \%$ CTAB (Hernández-Montes et al. 1973) was added and the sample centrifuged for $3 \mathrm{~min}$ at $5000 \mathrm{~g}$ at $4{ }^{\circ} \mathrm{C}$. The supernatants (containing solubilized theca and flagellum 
proteins) were collected. The pellets (nuclei) were washed thrice with $\mathrm{LB}$ and resuspended in $\mathrm{LB} / 0.5 \%$ SDS without Triton X-100. The protein concentration of all extracts was determined (Bradford 1976). Protein extracts were denatured with Laemmli's sample buffer (Laemmli 1970) and resolved through 10\% polyacrylamide-SDS gels and transferred to nitrocellulose membranes (Towbin et al. 1979). Membranes were incubated in 5\% dried skimmed milk in TBS/T (TBS-T: $150 \mathrm{mM}$ $\mathrm{NaCl}, 100 \mathrm{mM}$ Tris- $\mathrm{HCl}(\mathrm{pH}$ 7.6) plus $0.1 \%$ Tween 20) for $1 \mathrm{~h}$ to block non-specific binding sites. Then they were incubated overnight at $4{ }^{\circ} \mathrm{C}$ with the appropriate primary antibody diluted in blocking solution and washed. Incubation with the HRP-labeled secondary antibody was carried out for $1 \mathrm{~h}$ at $37^{\circ} \mathrm{C}$. HRP was developed by chemiluminescence kit, ECL.

\section{Immunoprecipitation}

Ten microliters of protein A-agarose were incubated with $0.4 \mu \mathrm{g}$ of the appropriate antibody for $5 \mathrm{~min}$. Then $1 \mathrm{mg}$ sperm protein from the selected extract to be assayed was added. The mixture was kept under constant agitation overnight at $4{ }^{\circ} \mathrm{C}$. Immune complexes were recovered by centrifugation ( $5000 \mathrm{~g}$ for $5 \mathrm{~min}$ ). Then the samples were washed thrice with NET buffer $(50 \mathrm{mM}$ Tris- $\mathrm{HCl}, 150 \mathrm{mM} \mathrm{NaCl}, 1 \mathrm{mM}$ EDTA, $20 \mathrm{mM}$ sodium orthovanadate, $20 \mathrm{mM}$ sodium molybdate, $50 \mathrm{mM}$ sodium fluoride, and $1 \%$ Triton $\mathrm{X}-100(\mathrm{pH} 7.5))$. The pellet was boiled for $5 \mathrm{~min}$ in $30 \mu \mathrm{l}$ Laemmli's sample buffer. Equal amounts of solubilized material were analyzed through $10 \%$ polyacrylamide-SDS gels, and the proteins revealed by Western blotting.

\section{Statistical analysis}

Data shown are the means \pm s.D. of at least three experiments. Statistically significant differences among conditions were analyzed. In Figs 3, 4A and C and 5, we used a one-way ANOVA test with Tukey's post hoc multiple comparison test. In Figs $4 \mathrm{~B}$ and 6, we used Student's t-test.

\section{Results}

\section{Identification and localization of Stat1 and Stat4 in guinea pig spermatozoa}

We decided to evaluate whether the transcription factors Stat1 and Stat4 were present in guinea pig spermatozoa. Immunoblot analysis of Triton X-100 sperm extracts revealed the presence of both Stat1 and Stat4 (Fig. 1A). The immunopositive band revealed in guinea pig sperm (S) comigrated with the ones from mouse testis $(\mathrm{T})$, brain (B), and HeLa cells $(\mathrm{H})$, which are well known for their high levels of Stat1 expression. A similar situation was observed in the immunoblot for Stat4, where the immunopositive band of guinea pig sperm (S) had the same electrophoretic mobility as the positive protein band from the mouse testis whole extract (T). Two negative controls were performed in guinea pig Triton X-100 sperm extracts: one without the first antibody and the other with preimmune serum in place of the first

A
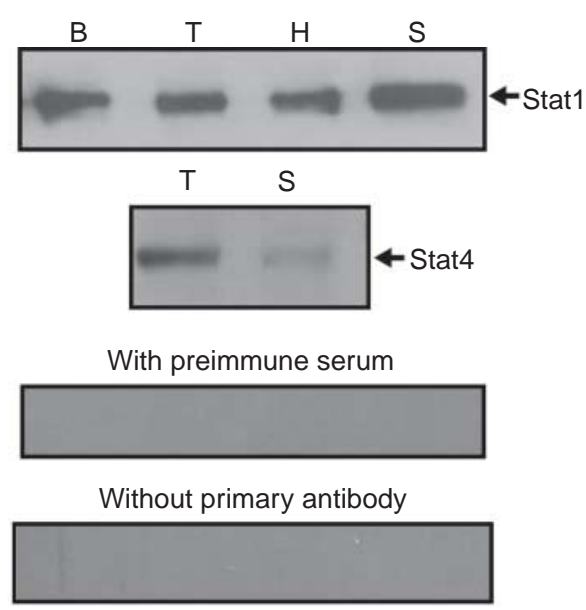

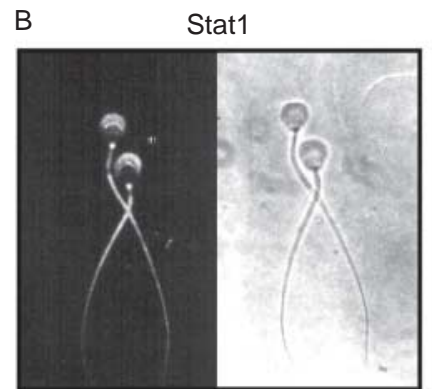

With preimmune serum

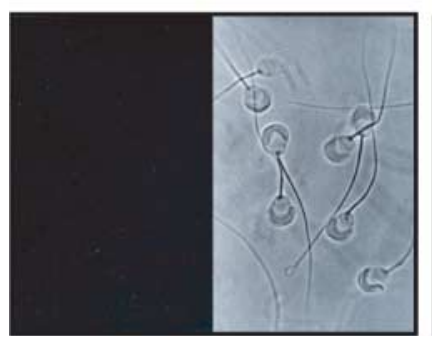

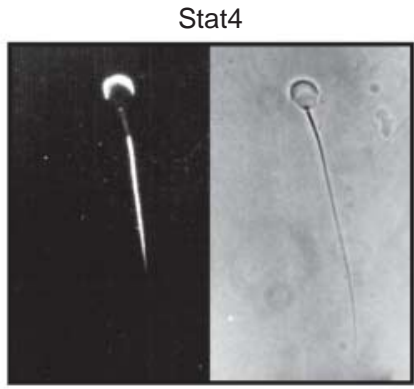

Without primary antibody

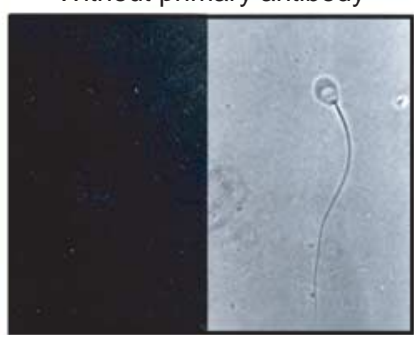

Figure 1 Stat 1 and Stat 4 identification in guinea pig spermatozoa. Noncapacitated ductus deferens and cauda epididymal spermatozoa were resuspended in lysis buffer. Triton X-100 extracts and controls were electrophoresed in 10\% SDS-PAGE. Positive expression of Stat1 and Stat4 is shown in A. Sperm protein (S) and positive controls: mouse brain (B), mouse testis $(T)$, and HeLa cells $(H)$. To test the specificity of the signal, samples as in the first panel were tested in western blot by avoiding the primary antibody or using a preimmune serum. B shows the immunolocalization of Stat1 and Stat 4 in fixed and permeabilized guinea pig sperm. Two negative controls were performed: spermatozoa were treated without the first antibody or stained with preimmune serum instead of the primary antibody. Each IIF is accompanied by its phase contrast image. 
antibody; negative results were obtained in both controls (Fig. 1A, lower panels).

In parallel, the cellular localization of both proteins was assessed by indirect immunofluorescence. As it can be noted (Fig 1B), Stat1 was detected in the acrosomal and neck regions and also along the flagellum, although less fluorescence was observed in the middle piece. Stat 4 was localized in the acrosomal region, along the flagellum with less fluorescence in the middle piece. In addition, negative controls were performed: 1) without the first antibody; and 2) with preimmune serum in place of the first antibody, both with negative results (Fig. 1B).

Stat4 has been detected in the PT of mouse sperm; but localization of Stat1 was not assessed (Herrada \& Wolgemuth 1997). As mentioned previously, we localized both Stat1 and Stat 4 in the Triton X-100 guinea pig sperm extracts (Fig. 1A). In acrosome-plasma membrane-free sperm, Stat1 was located mainly in the flagellum and a light fluorescence was also observed in the middle piece; on the other hand, Stat 4 was observed in the apical zone of the theca and along the flagellum (Fig. 2A).

The PT is a unique cytoskeletal mammalian sperm structure, which surrounds the nucleus and does not allow antibodies to enter the nucleus (Zepeda-Bastida, unpublished data). In addition, the sperm nucleus is very compact. Therefore, in order to detect Stat proteins within the nuclear compartment, we treated DTT-CTAB nuclei preparations (nuclei without nuclear membrane and PT) with heparin to promote slight nucleus decondensation before antibody staining. With this procedure, both Stat1 and Stat 4 were detected inside the nucleus (Fig. 2B). Both Stat 1 and Stat 4 located mainly in the apical zone of the nucleus and a postacrosomal cone was also detected. No fluorescence was observed at the equatorial region. For negative controls, DTT-CTAB nuclei were treated with the second antibody, but without the first one or, alternatively, with preimmune serum instead of the first antibody. Both controls gave negative results. Finally, the immunoblot analysis of protein extracts from Triton X-100 (Cyt), theca/flagellum (T/F), and nucleus (Nuc) revealed the presence of both Stat1 and Stat4 proteins in all subcellular fractions assayed (Fig. 2C). In addition, no contamination of the soluble fraction to the theca/flagellum and nucleus was found using immunodetection of the focal adhesion kinase as a marker (data not shown).

\section{Capacitation-induced phosphorylation of Stat1}

Phosphorylation at a tyrosine residue promotes dimerization of Stat proteins (Heim et al. 1995, Gupta et al. 1996, Ihle 1996), as well as their nuclear translocation (Shuai et al. 1994), and DNA-binding activity (Mowen \& David 1998). Sperm capacitation has been shown to be highly correlated with protein phosphorylation at tyrosine residues (Visconti et al. 1995a, 1995b). In order to know whether the capacitation process induces
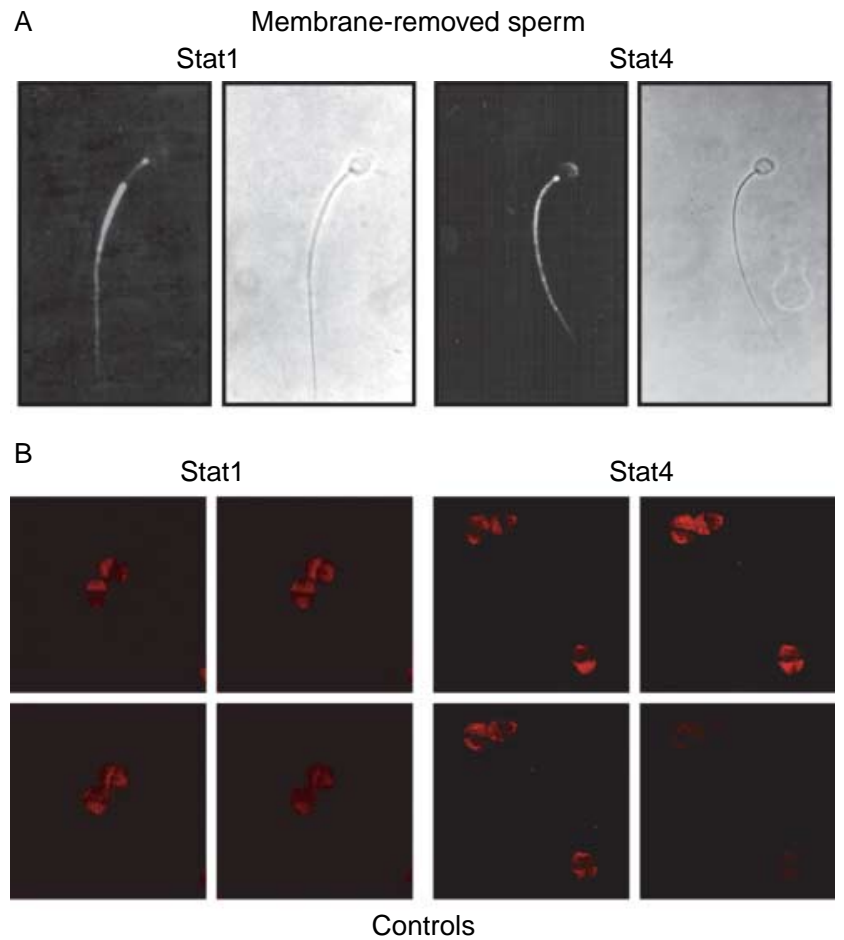

With preimmune serum Without primary antibody

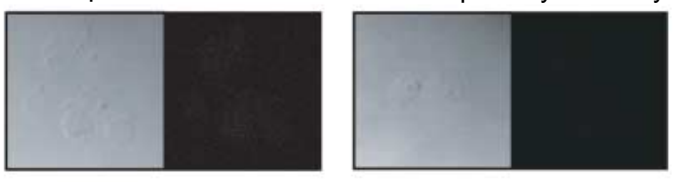

C
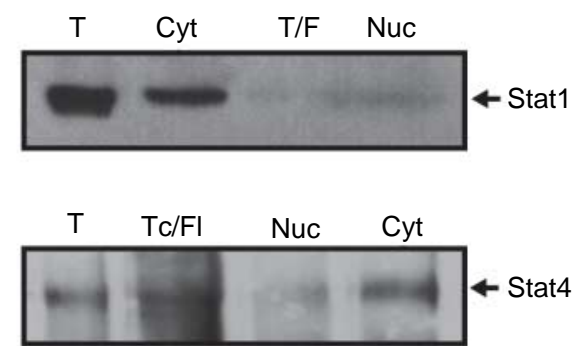

Figure 2 Determination of Stat1 and Stat4 in subcellular regions of guinea pig sperm. Non-capacitated sperm were treated with lysis buffer in order to solubilize the plasma membrane and the acrosomal membrane. Membrane-free spermatozoa were fixed and handled for immunofluorescence (A). Spermatic nuclei (DTT-CTAB) were fixed and stained with anti-Stat1 and anti-Stat4 antibodies; B shows different focal planes of the same preparation. Negative controls were as in Fig. 1 and each IIF is accompanied by its phase contrast image in A and B. Proteins from subcellular fractions: cytosol/membranes (Cyt), theca/flagellum $(\mathrm{T} / \mathrm{F})$, nuclei (Nuc), and mouse testis (T) were subjected to SDS-PAGE and Western blotting $(\mathrm{C})$.

changes in the pattern of Stat protein phosphorylation, Triton X-100 extracts from cells incubated in the capacitating medium, MCM-PL, were immunoprecipitated with anti-phosphotyrosine antibodies and immunoblotted with either anti-Stat1 or anti-Stat4. A significant increase in phosphorylation of Stat1 was detected after 30 min of capacitation; however, after 
60 min, phosphorylated Stat1 decreased to a basal level, as seen in non-capacitated sperm. The reciprocal experiment, immunoprecipitation with anti-Stat1 antibody and Western blotting with anti-phosphotyrosine, produced the same result (Fig. 3A). In contrast, phosphorylation of Stat 4 was not observed regardless of whether spermatozoa were capacitated or not (Fig. 3B).

It has been reported that tyrosine phosphorylation of the cytosolic Stats induces them to dimerize and translocate into the nucleus (Heim et al. 1995, Gupta et al. 1996, Ihle 1996). Therefore, we tested whether tyrosine phosphorylation decreases the cytosolic levels of Stat1. In comparison with non-capacitated spermatozoa at 30, 60, and 90 min of capacitation, we observed a significant decrease in cytosolic Stat1 protein (Fig. 4A); it is noteworthy that after $30 \mathrm{~min}$ of capacitation, there are no significant differences in Stat1

A
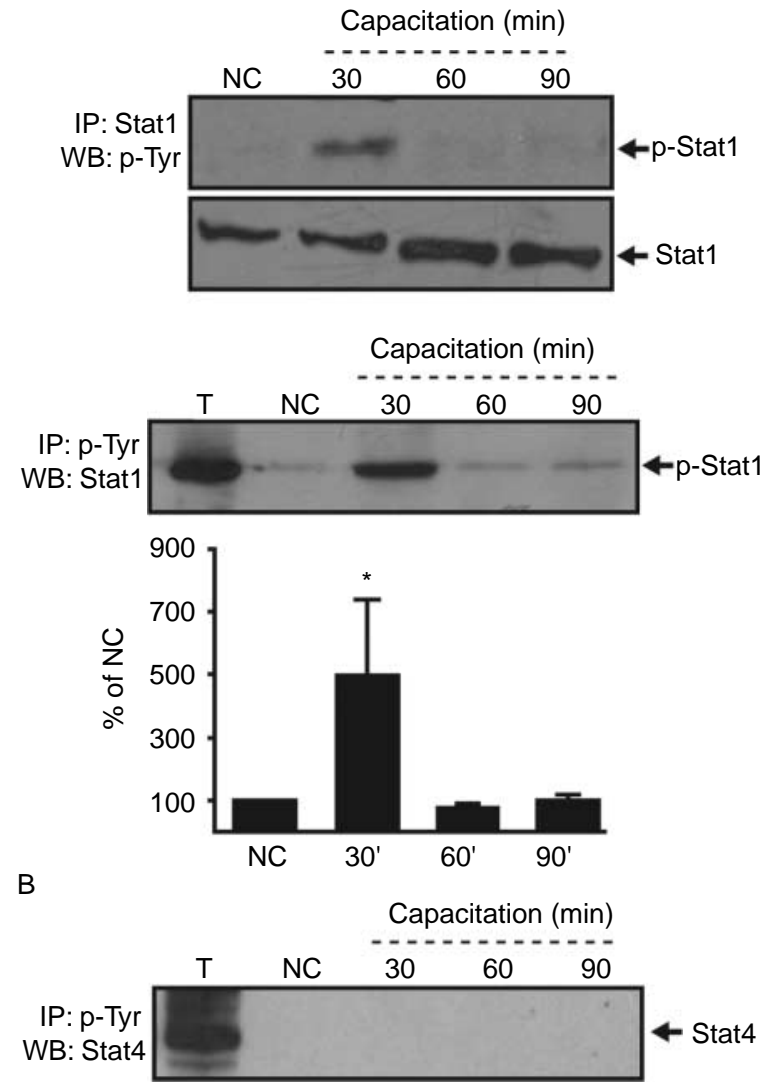

Figure 3 Capacitation induces phosphorylation of Stat1. Phosphorylation of Stat 1 and Stat 4 was tested in sperm incubated in MCM-PL capacitating medium for the indicated time. Triton X-100 extracts were immunoprecipitated with anti-phosphotyrosine antibody (p-Tyr) or anti-Stat1 antibody. Coprecipitated proteins were washed and subjected to western blotting using anti-Stat1 or anti-p-Tyr respectively (A). B shows immunoprecipitation from Triton X-100 extracts with anti-pTyr antibody and western blotting with anti-Stat 4 antibody. Quantification of Stat1 results by densitometry is shown below in A. Results are means \pm s.D. of triplicate experiments. ${ }^{*} P<0.05$ versus non-capacitated group (ANOVA). diminution $(P>0.05)$. In addition, when Stat1 was measured in the theca/flagella fraction, the protein was increased in capacitated sperm (Fig. 4B). When the cells were treated with genistein, a broad tyrosine kinase inhibitor, it prevented the decrease of cytosolic Stat1 protein. As a control, genistin, an inactive molecule structurally related to genistein, was tested. Genistin did not cancel Stat1 translocation (Fig. 4C). The result indicated the specificity of a tyrosine kinase inhibitor. Tubulin, which is observed in the sperm head (Dvorakova et al. 2005), was used as loading control. Gel densitometry was performed in each case and it is shown below each panel.

\section{Effect of PKA, PKC, and calcium on cytosolic Stat1}

Capacitated sperm exhibited a significant decrease in cytosolic Stat1 levels (Fig. 4). Additionally, inhibition of tyrosine kinase with genistein prevented the decrease in cytosolic Stat1 normally seen during capacitation (Fig. 4C). The activation of PKA plays a major role in capacitation. This is true also for the calcium-mediated activation of PKC. Thus, both protein kinases should regulate protein phosphorylation to promote activation. In addition, it has been demonstrated that PKA and PKC are involved in Stat1 activation (Lee \& Rikihisa 1998,Sakhalkar et al. 2005, Salonen et al. 2006). Therefore, we decided to determine whether treatment of sperm with inhibitors of both kinases and/or chelation of external calcium modified Stat1 translocation. The results shown in Fig. 5 indicate that by preventing PKA or PKC activation or by chelating calcium with EGTA, Stat1 translocation was blocked. The cytosolic Stat 1 concentration in the cells treated with inhibitors was not significantly different from that found in noncapacitated sperm.

\section{Phosphorylation of Stat1 during acrosome reaction}

Considering that phosphorylation of cytosolic Stat1 decreased some time after capacitation, and also that Stat 4 was never phosphorylated during the capacitation process, we decided to determine whether further changes in phosphorylation occur during the acrosome reaction (AR). To do this, synchronous $A R$ was induced with A23187 at 90 min capacitation, when Stat1 phosphorylation was decreased to basal level (Fig. 3A). Then Triton X-100 extracts were obtained and immunoprecipitated with anti-phosphotyrosine. Increased phosphorylation was observed in the western blot of immunoprecipitated proteins revealed with anti-Stat1 (Fig. 6A). However, as in capacitation, Stat4 was not phosphorylated in the acrosome-reacted spermatozoa (Fig. 6B). In order to determine whether AR induces changes in the location pattern of the Stat 1 in the nuclear compartment, nuclei obtained from non-capacitated and AR sperm were stained with anti-Stat1 antibodies. 
Stat1 was detected in the two nuclear hemispheres in both samples. In acrosome-reacted spermatozoa, Stat1 was detected in the equatorial region, forming a belt in the middle of the nucleus, which was not present in noncapacitated sperm (Fig. 6C).

A
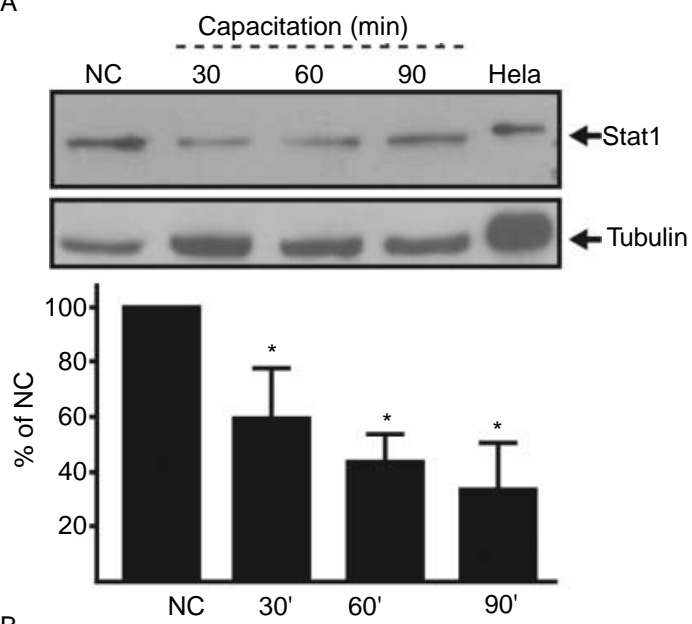

B
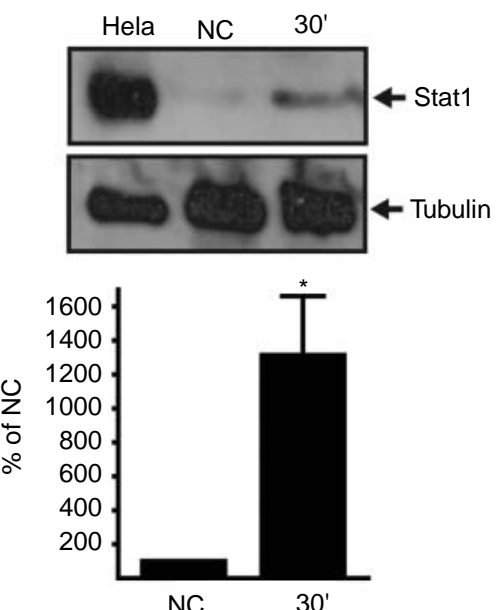

C
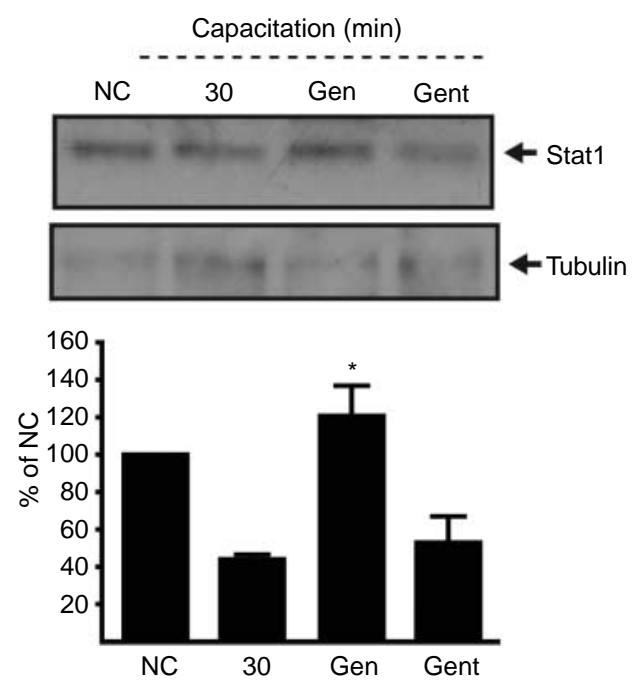

\section{Discussion}

In order for spermatozoa to acquire the ability to fertilize, capacitation and AR must occur as these cells travel through the female reproductive tract. The spermatozoon is a highly differentiated and transcriptionally silent cell; nevertheless, it does contain some transcription factors (Herrada \& Wolgemuth 1997, D'Cruz et al. 2001, Pittoggi et al. 2001). Among them, Stat1 was reported in human spermatozoa, whereas Stat 4 was reported in both human and mouse spermatozoa; mouse Stat 4 was located in the sperm PT (Herrada \& Wolgemuth 1997, D'Cruz et al. 2001).

Recent reports suggest a new view, in which sperm deliver not only the male genome to the egg, but also several crucial molecules needed for fertilization as well as development of the embryo (Ostermeier et al. 2002, 2004, 2005, Saunders et al. 2002, Piston et al. 2004, Ainsworth 2005). Here, we report the presence of both Stat 1 and Stat 4 transcription factors and their location in guinea pig sperm subcellular fractions. Additionally, we show that the Stat1phosphorylated state varies during capacitation (Fig. 3A) and AR (Fig. 6A). Interestingly, Stat1 phosphorylation during capacitation occurred together with a decrease in the cytosolic level of Stat1, which paralleled an increase in the concentration of Stat1 in the theca/flagellum fraction (Fig. 4A and B).

As can be noted in Fig. 3, Stat1, but not Stat4, was phosphorylated in response to capacitation, suggesting that different signal pathways work in the sperm to activate two members of the same family. The increase in Stat1 phosphorylation was transient, peaking at $30 \mathrm{~min}$ of incubation in MCM-PL medium. Then, it decreased to basal levels at 60 and 90 min of capacitation. Intriguingly, cytosolic Stat1 was dephosphorylated, indicating the presence of phosphatases. Nevertheless, once the AR began, Stat1 became highly phosphorylated once again (Fig. 6). These results also implicate that the kinasemediated phosphorylation of Stat1 is a tightly regulated process: the first phosphorylation would allow Stat1 to move to cellular compartments such as the theca, flagellum, and nucleus, all of which enter the egg at fertilization. The second phosphorylation would allow Stat1 to be active during the first rounds of transcription in the male pronucleus.

Figure 4 Stat 1 concentration decreases in the cytosol of capacitated sperm. Triton X-100 extracts obtained from capacitated sperm for the times indicated were prepared for immunoblot analysis, $100 \mu \mathrm{g}$ protein were loaded per lane and immunoblotted using anti-Stat1 (A). Extracts obtained from theca/flagella fraction were immunoblotted with anti-Stat1 (B). Sperm were preincubated in $\mathrm{NaCl}$ with $100 \mu \mathrm{M}$ genistein or $100 \mu \mathrm{M}$ genistin, then capacitated in MCM-PL medium plus $100 \mu \mathrm{M}$ genistein or $100 \mu \mathrm{M}$ genistin for $30 \mathrm{~min}$. Proteins were subjected to Western blotting (C). Densitometry data of triplicate experiments were normalized against tubulin, used as loading control. Graphs show means \pm s.D. ${ }^{*} P<0.05$ versus non-capacitated group (ANOVA) is shown in A and B, whereas in C $* P<0.05$ versus capacitated group is shown. 


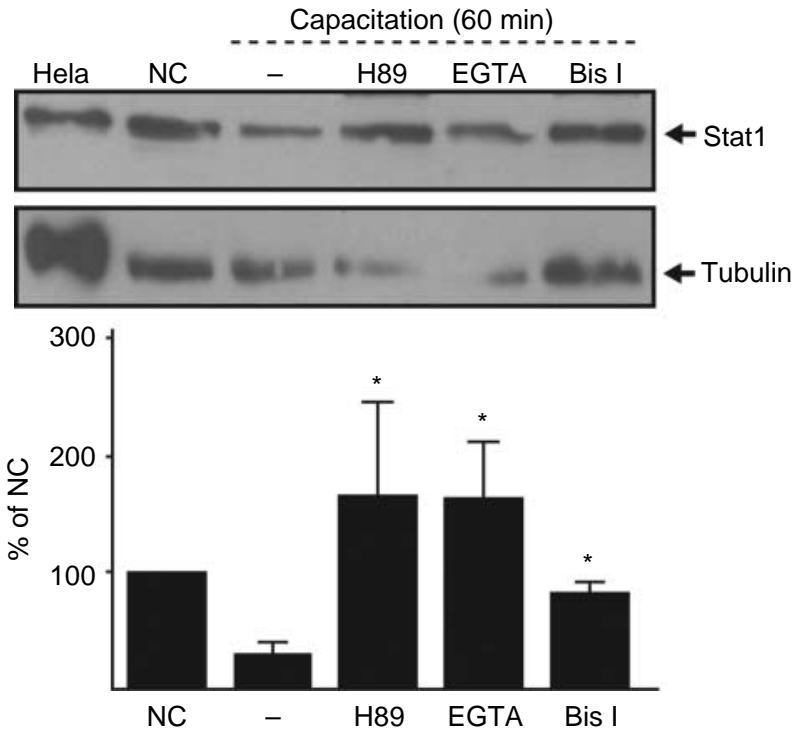

Figure 5 Effect of protein kinase inhibitors on the cytosolic Stat1 protein in capacitated sperm. Triton X-100 extracts were obtained from noncapacitated (NC) and 60-min MCM-PL capacitated sperm or this last sample plus the following kinase inhibitors: 1 mMEGTA, $30 \mu \mathrm{M} \mathrm{H} 89$, and $1 \mu \mathrm{M}$ bisindolylmaleimide I (Bis I). The extracts were immunoblotted with anti-Stat1 antibody. Stat1 cytosolic levels were normalized against tubulin. Results in the graphs show means \pm s.D. of triplicate experiments. $* P<0.05$ versus capacitated group (ANOVA).

The data indicate that Stat1 phosphorylation in capacitated and acrosome-reacted spermatozoa could be significant from a functional point of view. Supporting this idea is the large decrease of Stat 1 concentration in the cytosol, together with the observed increase in the theca/flagellum fraction (Fig. 4). Thus, it may be suggested that phosphorylation signals induce a change in the localization of Stat1. Furthermore, genistein, a broad tyrosine kinase inhibitor, canceled the migration of Stat1.

During capacitation, cAMP levels increase in response to production of reactive oxygen species, leading to PKA activation. Blocking this signal pathway inhibits capacitation (White \& Aitken 1989, Visconti et al. 1997, Breitbart \& Naor 1999). Moreover, in spermatozoa, activation of PKA increases the level of tyrosinephosphorylated proteins (Thundathil et al. 2002). In addition, during capacitation, intracellular calcium is increased, which in turn would induce activation of PKC and regulation of tyrosine phosphorylation (Visconti et al. 1995a, 1995b, Luconi et al. 1996, Leclerc et al. 1998, Baker et al. 2004). Although PKC participation in capacitation remains controversial, there is evidence supporting the activation of PKC during capacitation (Furuya et al. 1993, Cohen et al. 2004, Breitbart et al. 2006, O'flaherty et al. 2006). In this work, inhibition of Stat1 translocation was observed in spermatozoa treated with EGTA, $\mathrm{H}-89$, or Bis I. Thus, results in capacitation clearly show that for cytosolic Stat1 translocation to occur, all PKA, PKC, and calcium are needed to promote the phosphorylation of Stat1. It is well known that PKA activation increases tyrosine phosphorylation; also the phosphorylated PKA participates in Stat tyrosine phosphorylation (Deo et al. 2004, Sakhalkar et al. 2005). It is quite possible that PKA, PKC, and calcium are involved
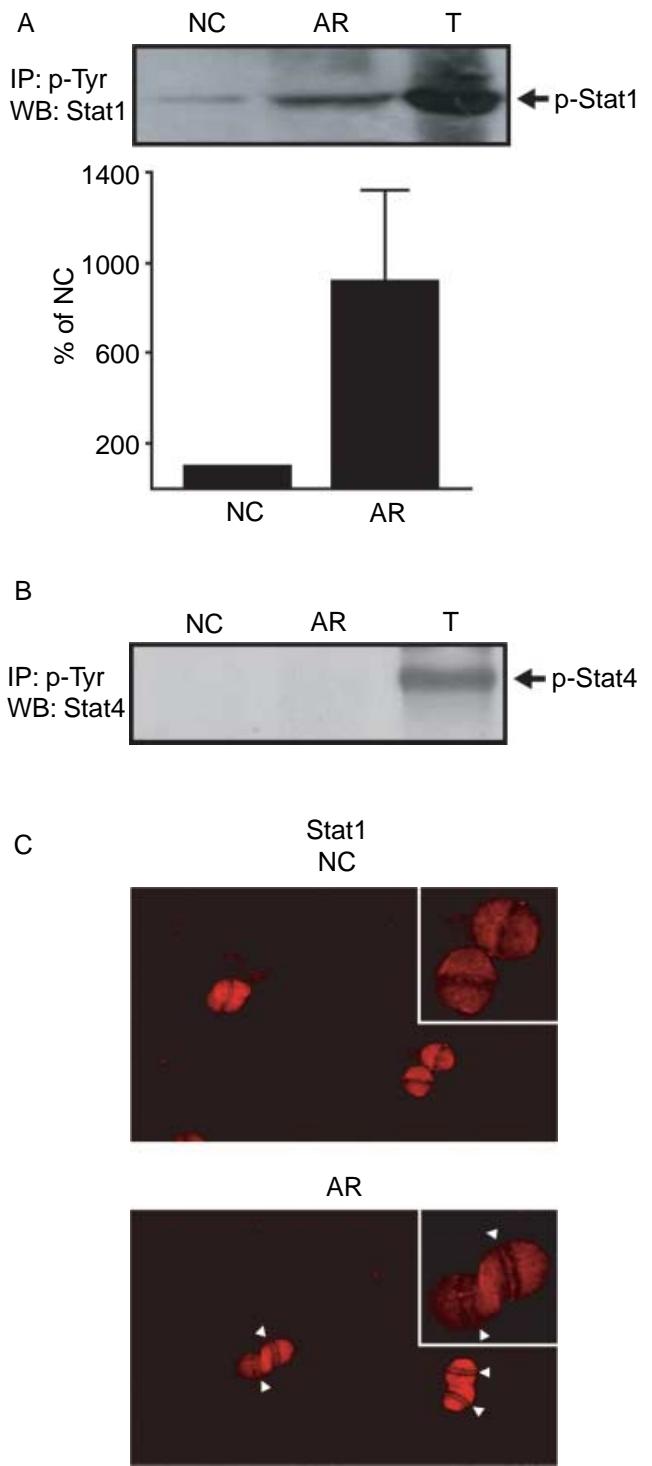

Figure 6 Acrosome reaction enhances tyrosine phosphorylation of Stat1. Phosphorylation of Stat1 and Stat4 was determined in acrosome-reacted spermatozoa. In spermatozoa capacitated in MCM-PL for $90 \mathrm{~min}$, the acrosomal reaction was induced with $1.3 \mu \mathrm{M}$ calcium ionophore A23187. Acrosome-reacted spermatozoa were collected at $5000 \mathrm{~g}$. Pelleted spermatozoa were added with lysis buffer. Triton X-100 extracts immunoprecipitated with anti-p-Tyr were subjected to immunoblot analysis and revealed with anti-Stat1 (A). Quantification of the results by densitometry is shown below in A. Mean \pm s.D. of at least three experiments. ${ }^{*} P<0.05$ versus noncapacitated group. B, Stat 4 phosphorylation in Triton X-100 extracts of spermatozoa as in A. Acrosome-reacted (AR) or non-capacitated sperm (NC) extracts are shown alongside with mouse testis (T) extracts as positive control. Nuclei (DTT-CTAB) from noncapacitated and acrosome-reacted spermatozoa were fixed and stained with anti-Stat1. Arrows indicate a belt area formed by Stat 1 in the middle of the nucleus in AR sperm (C). 
in the same signal pathway, where either PKA is necessary to activate PKC (Sakhalkar et al. 2005), or calcium and CAMP work together to activate PKA. Subsequently, calcium channels would become activated with a concomitant activation of PKC through PLC $\gamma$. However, that scenario would only be possible in the late phase of capacitation (Breitbart 2002). On the other hand, it has recently been shown that PKC is active during capacitation, but activation of PKA leads to an inhibition of PKC (Cohen et al. 2004, Breitbart et al. 2006). It is possible that PKC-dependent Stat1 phosphorylation occurs before PKA blocks PKC activity. In the short term, this would result in the first calcium waves. If that were the case, it would indicate that two different signal pathways converge in a common substrate: a candidate is Stat 1 by itself, and another could be a Src-family member (Chang et al. 2004, Deo et al. 2004, Salonen et al. 2006), like c-yes (Leclerc \& Goupil 2002). In addition, another non-receptor tyrosine kinase like PYK2 might be involved (Takaoka et al. 1999, Chieffi et al. 2003).

As mentioned previously, Stat1 becomes phosphorylated a second time during $A R$; interestingly, during $A R$, intranuclear Stat1 was reorganized (Fig. 6C). A question that comes to mind is whether intranuclear Stat1 is moving toward the site where the first transcription will take place. The fact that Stat1 locates at the internuclear equatorial zone of the acrosome-reacted sperm is very suggestive.

The present study provides evidence that the transcription factor Stat1, but not Stat4, can be activated during the last two steps of sperm preparation for fertilization. In addition, we provide evidence for the mechanism by which a transcription factor can move toward spermatic structures that will enter the female oocyte during fertilization. In opposition to somatic cells, where transcription factors move directly from the cytoplasm into the nucleus, in sperm the theca does not allow a direct movement. Thus, the strategy has to be different: transcription factors should move into the theca and flagellum and wait until the fertilization process begins to reach their final destination, the pronucleus. In addition, we show two kinases involved in Stat1 activation. Current work in our lab is underway to establish the signal pathway involved in Stat1 activation.

\section{Acknowledgements}

This work was supported by Consejo Nacional de Ciencia y Tecnología (Conacyt)-Mexico (grant 41725-Q to AM). Y B and A Z were supported by a Conacyt doctoral fellowship. The technical assistance of M en C Ana Lilia Roa Espitia, Víctor Cortés, M en C Alma Olivia Monrroy Lopez and QBP, Blanca Estela Reyes Marquez is acknowledged. We wish to thank Dr J Eduardo Perez Salazar for the critical reading and comments on the manuscript. The authors declare that there is no conflict of interest that would prejudice the impartiality of this scientific work.

\section{References}

Ainsworth C 2005 Cell biology: the secret life of sperm. Nature 436 770-771.

Baker MA, Hetherington L, Ecroyd H, Roman SD \& Aitken RJ 2004 Analysis of the mechanism by which calcium negatively regulates the tyrosine phosphorylation cascade associated with sperm capacitation. Journal of Cell Science 117 211-222.

Bradford MM 1976 A rapid and sensitive method for the quantitation of microgram quantities of protein utilizing the principle of protein-dye binding. Analytical Biochemistry 72 248-254.

Breitbart H 2002 Role and regulation of intracellular calcium in acrosomal exocytosis. Journal of Reproductive Immunology $\mathbf{5 3}$ 151-159.

Breitbart H \& Naor Z 1999 Protein kinases in mammalian sperm capacitation and the acrosome reaction. Reviews of Reproduction 4 151-159.

Breitbart H, Rubinstein S \& Etkovit N 2006 Sperm capacitation is regulated by the crosstalk between protein kinase $\mathrm{A}$ and $\mathrm{C}$. Molecular and Cellular Endocrinology 252 247-249.

Brivanlou AH \& Darnell JE 2002 Signal transduction and the control of gene expression. Science 295 813-818.

Chang YJ, Holtzman MJ \& Chen CC 2004 Differential role of Janus family kinases (JAKs) in interferon-gamma-induced lung epithelial ICAM-1 expression: involving protein interactions between JAKs, phospholipase C gamma, c-Src, and Stat1. Molecular Pharmacology 65 589-598.

Chieffi P, Barchi M, DiAgostino S, Rossi P, Tramontano D \& Geremia R 2003 Prolin-rich tyrosine kinase2 (PYK2) expression and localization in mouse testis. Molecular Reproduction and Development 65 330-335.

Cho SS, Bacon CM, Sudarshan C, Rees RC, Finbloom D, Pine R \& O'Shea JJ 1996 Activation of STAT4 by IL-12 and IFN-alpha: evidence for the involvement of ligand-induced tyrosine and serine phosphorylation. Journal of Immunology 157 4781-4789.

Cohen G, Rubinstein S, Gur Y \& Breitbart H 2004 Crosstalk between protein kinase $A$ and $C$ regulates phospholipase $D$ and $F$-actin formation during sperm capacitation. Developmental Biology 267 230-241.

Darnell JE 1997 STATs, and gene regulation. Science 277 1630-1635.

Darnell JE 1998 Studies of IFN-induced transcriptional activation uncover the Jak-Stat pathway. Journal of Interferon \& Cytokine Research 18 549-554.

Darnell JE, Kerr IM \& Stark GR 1994 Jak-STAT pathways and transcriptional activation in response to IFNs and other extracellular signaling proteins. Science 264 1415-1421.

D'Cruz OJ, Vassilev AO \& Uckun FM 2001 Members of the Janus kinase/signal transducers and activators of transcription (JAK/STAT) pathway are present and active in human sperm. Fertility and Sterility $76258-266$.

Deo DD, Bazan NG \& Hunt JD 2004 Activation of platelet-activating factor receptor-coupled G alpha q leads to stimulation of Src and focal adhesion kinase via two separate pathways in human umbilical vein endothelial cells. Journal of Biological Chemistry 279 3497-3508.

Dvorakova K, Moore HDM, Sebkova N \& Palecek J 2005 Cytoskeleton localization in the sperm head prior to fertilization. Reproduction $13061-69$.

Furuya S, Endo Y, Osumi K, Oba M \& Suzuki S 1993 Effects of modulators of protein kinase $\mathrm{C}$ on human sperm capacitation. Fertility and Sterility 59 1285-1290.

Gupta S, Yan H, Wong LH, Ralph S, Krolewski J \& Schindler C 1996 The $\mathrm{SH} 2$ domains of Stat 1 and Stat2 mediate multiple interactions in the transduction of IFN-alpha signals. EMBO Journal 15 1075-1084.

Heim MH, Kerr IM, Stara GR \& Darnell JE 1995 Contribution of STAT $\mathrm{SH} 2$ groups to specific interferon signaling by the Jak-STAT pathway. Science 267 1347-1349. 
Hernández-Montes H, Iglesias G \& Mújica A 1973 Selective solubilization of mammalian spermatozoa structures. Experimental Cell Research 76 437-440.

Herrada G \& Wolgemuth DJ 1997 The mouse transcription factor Stat 4 is expressed in haploid male germ cells and is present in the perinuclear theca of spermatozoa. Journal of Cell Science 110 1543-1553.

Ihle JN 1996 STATs: signal transducers and activators of transcription. Cell 84 331-334.

Ihle JN 2001 The Stat family in cytokine signaling. Current Opinion in Cell Biology 13 211-217.

Jacobson NG, Szabo SJ, Guler ML, Gorham JD \& Murphy KM 1996 Regulation of interleukin-12 signalling during $\mathrm{T}$ helper phenotype development. Advances in Experimental Medicine and Biology 409 61-73.

Kisseleva T, Bhattacharya S, Braunstein J \& Schindler CW 2002 Signaling through the JAK/STAT pathway, recent advances and future challenges. Gene 285 1-24.

Laemmli UK 1970 Cleavage of structural proteins during the assembly of the head of bacteriophage T4. Nature 227 680-685.

Leaman DW, Leung S, Li X \& Stark GR 1996 Regulation of STATdependent pathways by growth factors and cytokines. FASEB Journal 10 1578-1588.

Leclerc P \& Goupil S 2002 Regulation of the human sperm tyrosine kinase c-yes. Activation by cyclic adenosine 3', $5^{\prime}$-monophosphate and inhibition by $\mathrm{Ca}(2+)$. Biology of Reproduction 67 301-307.

Leclerc P, de Lamirande E \& Gagnon C 1998 Interaction between $\mathrm{Ca}^{2+}$, cyclic $3^{\prime}, 5^{\prime}$ adenosine monophosphate, the superoxide anion, and tyrosine phosphorylation pathways in the regulation of human sperm capacitation. Journal of Andrology 19 434-443.

Lee EH \& Rikihisa Y 1998 Protein kinase A-mediated inhibition of gamma interferon-induced tyrosine phosphorylation of Janus kinases and latent cytoplasmic transcription factors in human monocytes by Ehrlichia chaffeensis. Infection and Immunity 66 2514-2520.

Luconi M, Krausz C, Forti G \& Baldi E 1996 Extracellular calcium negatively modulates tyrosine phosphorylation and tyrosine kinase activity during capacitation of human spermatozoa. Biology of Reproduction 55 207-216.

Moreno-Fierros L, Hernandez EO, Salgado ZO \& Mujica A 1992 F-actin in guinea pig spermatozoa: its role in calmodulin translocation during acrosome reaction. Molecular Reproduction and Development 33 172-181.

Mowen K \& David M 1998 Role of the STAT1-SH2 domain and STAT2 in the activation and nuclear translocation of STAT1. Journal of Biological Chemistry 273 30073-30076.

Ocampo J, Mondragon R, Roa-Espitia AL, Chiquete-Felix N, Salgado ZO \& Mujica A 2005 Actin, myosin, cytokeratins and spectrin are components of the guinea pig sperm nuclear matrix. Tissue and Cell 37 293-308.

O'Flaherty C, Lamirande E \& Gagnon C 2006 Positive role of reactive oxygen species in mammalian sperm capacitation: triggering and modulation of phosphorylation events. Free Radical Biology and Medicine 41 528-540.

O'Shea JJ, Gadina M \& Schreiber RD 2002 Cytokine signaling in 2002: new surprises in the Jak/Stat pathway. Cell 109 S121-S131.

Ostermeier GC, Dix DJ, Miller D, Khatri P \& Krawetz SA 2002 Spermatozoal RNA profiles of normal fertile men. Lancet $\mathbf{3 6 0}$ 772-777.

Ostermeier GC, Miller D, Huntriss JD, Diamond MP \& Krawetz SA 2004 Reproductive biology: delivering spermatozoan RNA to the oocyte. Nature 429154.

Ostermeier GC, Goodrich RJ, Moldenhauer JS, Diamond MP \& Krawetz SA 2005 A suite of novel human spermatozoal RNAs. Journal of Andrology 26 70-74.

Piston F, Dorado G, Martin A \& Barro F 2004 Cloning and characterization of a gamma-3 hordein mRNA (cDNA) from Hordeum chilense (Roem. et Schult.). Theoretical and Applied Genetics 108 1359-1365.
Pittoggi C, Magnano AR, Sciamanna I, Giordano R, Lorenzini R \& Spadafora C 2001 Specific localization of transcription factors in the chromatin of mouse mature spermatozoa. Molecular Reproduction and Development 60 97-106.

Rogers BJ \& Yanagimachi R 1975 Retardation of guinea pig sperm acrosome reaction by glucose: the possible importance of pyruvate and lactate metabolism in capacitation and the acrosome reaction. Biology of Reproduction 13 568-575.

Sakhalkar SP, Patterson EB \& Khan MM 2005 Involvement of histamine $\mathrm{H} 1$ and $\mathrm{H} 2$ receptors in the regulation of STAT- 1 phosphorylation: inverse agonism exhibited by the receptor antagonists. International Immunopharmacology 5 1299-1309.

Salonen T, Sareila O, Jalonen U, Kankaanranta H, Tuominen R \& Moilanen E 2006 Inhibition of classical PKC isoenzymes downregulates STAT1 activation and iNOS expression in LPS-treated murine J774 macrophages. British Journal of Pharmacology 147 790-799.

Saunders CM, Larman MG, Parrington J, Cox LJ, Royse J, Blayney LM, Swann K \& Lai FA 2002 PLC $\zeta$ : a sperm-specific trigger of $\mathrm{Ca}(2+)$ oscillations in eggs and embryo development. Development 129 3533-3544.

Schindler C 1999 Cytokines and JAK-STAT signaling. Experimental Cell Research 253 7-14.

Shuai K, Horvath CM, Huang LH, Qureshi SA, Cowburn D \& Darnell JE 1994 Interferon activation of the transcription factor Stat1 involves dimerization through $\mathrm{SH}$ 2-phosphotyrosyl peptide interactions. Cell 76 821-828.

Takaoka A, Tanaka N, Mitani Y, Miyazaki T, Fuji H, Sato M, Kovarik P, Decker T, Schlessinger J \& Taniguchi T 1999 Protein tyrosine kinase Pyk2 mediates the Jak-dependent activation of MAPK and Stat1 in IFN-gamma, but not IFN-alpha, signaling. EMBO Journal 18 2480-2488.

Thundathil J, Lamirande E \& Gagnon C 2002 Different signal transduction pathways are involved during human sperm capacitation induced by biological and pharmacological agents. Molecular Human Reproduction 8 811-816.

Towbin H, Staehelin T \& Gordon J 1979 Electrophoretic transfer of proteins from polyacrylamide gels to nitrocellulose sheets: procedure and some applications. PNAS 76 4350-4354.

Trejo R \& Mujica A 1990 Changes in calmodulin compartmentalization throughout capacitation and acrosome reaction in guinea pig spermatozoa. Molecular Reproduction and Development $\mathbf{2 6}$ 366-337.

Visconti PE, Bailey JL, Moore GD, Pan D, Olds-Clarke P \& Kopf GS 1995a Capacitation of mouse spermatozoa. I. Correlation between the capacitation state and protein tyrosine phosphorylation. Development 121 1129-1137.

Visconti PE, Moore GD, Bailey JL, Leclerc P, Connors SA, Pan D, OldsClarke P \& Kopf GS 1995b Capacitation of mouse spermatozoa. II. Protein tyrosine phosphorylation and capacitation are regulated by a cAMP-dependent pathway. Development 121 1139-1150.

Visconti PE, Johnson LR, Oyaski M, Fornes M, Moss SB, Gerton GL \& Kopf GS 1997 Regulation, localization, and anchoring of protein kinase A subunits during mouse sperm capacitation. Developmental Biology 192 351-363.

White DR \& Aitken RJ 1989 Relationship between calcium, cyclic AMP, ATP, and intracellular $\mathrm{pH}$ and the capacity of hamster spermatozoa to express hyperactivated motility. Gamete Research 22 163-177.

Yanagimachi R 1995 Is an animal model needed for intracytoplasmic sperm injection (ICSI) and other assisted reproduction technologies? Human Reproduction 10 2525-2526.

Received 11 October 2006

First decision 9 November 2006

Revised manuscript received 20 June 2007

Accepted 25 June 2007 